\title{
Simulated Experiment of Water-Sand Inrush across Overlying Strata Fissures Caused by Mining
}

\author{
Guibin Zhang, ${ }^{1}$ Hailong Wang $\mathbb{D}^{1,2}$ Shenglei Yan, ${ }^{1,2}$ Chuanyang Jia, ${ }^{1}$ and Xiaoyuan Song ${ }^{1}$ \\ ${ }^{1}$ School of Civil Engineering and Architecture, Linyi University, Linyi 276000, China \\ ${ }^{2}$ Shandong Detong Road and Bridge Construction Engineering Co., Ltd, Weihai 264200, China \\ Correspondence should be addressed to Hailong Wang; whlmlp@163.com
}

Received 29 October 2020; Revised 12 November 2020; Accepted 21 November 2020; Published 30 November 2020

Academic Editor: Bin Gong

Copyright (C) 2020 Guibin Zhang et al. This is an open access article distributed under the Creative Commons Attribution License, which permits unrestricted use, distribution, and reproduction in any medium, provided the original work is properly cited.

\begin{abstract}
In western region of China, the water-sand inrush across overlying strata fissures caused by mining threatens the mine safety production seriously. In order to study the development of water-sand inrush across overlying strata fissures caused by mining, a simulated test system consisted of load support bracket, laboratory module, confined water module, coal seam mining simulator, storage tank, and control system is developed. The combination of coal bearing strata in the south of Shendong mining area is looked on as the engineering background, and a series of new nonhydrophilic composite materials with lower intensity are developed to simulate the coal measure strata. The excavation of physical model can reproduce the whole process of water-sand inrush across overlying strata fissures caused by mining to the life. Under the action of mining and water pressure, after the fourth excavation, the mining-induced vertical fractures of overlying strata pass through the entire bedrock and connect the unconsolidated sand bed, which serves as pathways between the unconsolidated sand bed and working face, triggering water-sand inrush. The water pump suddenly accelerates, and the water yield suddenly increases to the extreme value of $150 \mathrm{~L} / \mathrm{h}$. The water pressure rapidly drops to $0 \mathrm{MPa}$, and a small amount of colored sand enters into the fractures of overlying strata and flows out with the water. The distribution of support pressure around the working face can be divided into 4 areas obviously, that is, the original stress area, the stress-concentrated area, the stress-released area, and the stress restoration area. Test results show that the system is stable and reliable, which have important significance for studying the formation mechanism of water-sand inrush across overlying strata fissures further.
\end{abstract}

\section{Introduction}

In western region of China, the thickness of coal seam is larger, the buried depth is shallower, the bedrock is thinner, and there is also a thick unconsolidated sand bed near the surface [1-4]. The mining of such coal seam can lead to intense overlying strata movement and impact wider range. The overlying strata are difficult to form a stable support structure. The fractures of overlying strata are fully developed, which can even reach the surface and form larger ground fissures and sidestepped subsidence $[5,6]$. If the watery of the thick unconsolidated sand bed near the surface is good, the mixture of water-sand will inrush the coal working face across overlying strata fissures, which may lead to property losses and even casualties, and seriously threaten the mine safety production [7-15]. In order to get rid of the serious problems of water-sand inrush across overlying strata fissures during coal resource development, studies about deformation and failure of overlying strata, development and propagation of fractures, and seepage and inrush of water-sand are badly needed, which are the basis of researching the mechanism of water-sand inrush across overlying strata fissures [16-20]. The mechanism and influencing factor of water-sand inrush across overlying strata fissures are difficult to obtain by field observation because of the concealment of underground excavation engineering; laboratory tests become an effective way of solving this problem [2124]. Some scholars have designed or optimized the relevant test equipment and carried out the simulated test research.

Liang et al. [25] and Tang et al. [26] designed a sealed container equipped with pressure and measuring devices, which was $0.8 \mathrm{~m}$ high and $1.8 \mathrm{~m}$ in diameter. The process of 
water-sand inrush was simulated, and influencing factors of water-sand inrush were determined initially. Sui et al. [27, 28] refitted the TST-70 permeameter. The overlying strata deformation and failure types and mechanisms caused by permeation in caving zone and fracture zone were simulated; the aperture of fracture and initial water pressure of waterbearing stratum were the key factors influencing water-sand inrush in underground mining face. Yang et al. [29, 30] designed an experimental facility for simulating the migration characteristics and inrush mechanism of water-sand mixture, which included an experiment tank and an experiment barrel.

Although these previous studies have provided a good understanding of the mechanism and influencing factor of water-sand inrush across overlying strata fissures, the existing test systems still have some deficiencies. (1) The existing test systems cannot reproduce the whole process of watersand inrush across overlying strata fissures caused by mining to the life, which can only reproduce the happening process of water-sand inrush. (2) The structure, shape, and size of water-sand inrush channels are set artificially, which are not formed under the influence of mining and water pressure. (3) During the working face mining, the deformation and failure of overlying strata, fissure extension of overlying strata, and formation of water-sand channels cannot be observed directly. (4) After the working face mining, the spatial structure form of overlying strata and the distribution form sand and water channel cannot be exposed directly. In order to overcome the deficiencies of existing test systems, the simulated test system for water-sand inrush across overlying strata fissures caused by mining is developed. The coal measure strata in the western region of China are looked on as the engineering background, and the new nonhydrophilic composite materials with lower intensity are developed to simulate the coal measure strata. The excavation of model can reproduce the whole process of water-sand inrush across overlying strata fissures caused by mining to the life.

\section{Test System Structure}

The simulated test system for water-sand inrush across overlying strata fissures caused by mining consisted of load support bracket, laboratory module, confined water module, coal seam mining simulator, storage tank, servo control system of water pressure and water yield, and servo control system of displacement and stress, as shown in Figure 1.

2.1. Load Support Bracket. The load support bracket consisted of base, frame, supporting structure of hydraulic cylinder, and reaction frame, as shown in Figure 1. Two legs are fixed on the base. Two hydraulic cylinders are fixed on the top beam, which is supported firmly by the two legs. Two squeeze heads for providing lateral restriction are installed on the inside of the legs. Two deformation resistant supports are installed between the leg and the beam for enhancing the bearing capacity and deformation resistant capacity of the frame.
2.2. Laboratory Module. The structure of laboratory module is shown in Figure 2. The effective sizes of length, width, and height are $1200 \mathrm{~mm}, 400 \mathrm{~mm}$, and $700 \mathrm{~mm}$, respectively. In order to observe the deformation and failure of overlying strata, fissure extension of overlying strata, and formation of water-sand channels directly, a piece of complete organic glass plate with high strength and good transparence is selected as the front baffle plate. Two deformation resistant beams are configured to reduce the deformation of the front baffle plate and enhance the airproof of the laboratory chamber. A piece of complete corrosion resistant plate with $20 \mathrm{~mm}$ thickness is selected as the back baffle plate that enhances the deformation resistant capacity of the laboratory chamber. The junction surfaces between baffle plates and vertical plates are sealed by rubber sealing strips, which are installed in the installation channels. A water-sand collecting tank is located on the bottom of laboratory module.

2.3. Confined Water Module. Confined water module can supply water to the laboratory module, which is connected by connecting pieces with hydraulic cylinders. At the bottom of the confined water module, 32 drainage holes with $4 \mathrm{~mm}$ diameter are equally distributed. In order to improve the sealing performance of the laboratory module, an installation channel with $5 \mathrm{~mm}$ depth and $15 \mathrm{~mm}$ width is reserved for installing the seal ring. Confined water module can also be used as the load head, which can provide vertical load to the laboratory model.

2.4. Coal Seam Mining Simulator. The manual excavation is the common method for excavating the traditional similar material model, which has the following drawbacks: (1) the process of excavation is difficult to maintain a constant excavation step distance and speed. (2) It is difficult to achieve 3D simulation of coal mining. (3) In the process of excavation, the caving roof will fall into the operating space and impact the excavation of similar material model. (4) It is necessary to remove the baffle plates of laboratory module for the excavation of similar material model, which reduces the plugging ability of laboratory module.

Considering the above drawbacks, a coal seam mining simulator is designed, which consists of 3 parts: (1) 13 stainless steel plates, which is used to simulate the coal seam, the specific size and arrangement are shown in Figure 3(a). The size of steel plate can be changed with the change of geologic and mining condition and ratio of similitude of the physical model. (2) 7 rollers, the purposes are to support upper load and reduce the frictional drag in the process of drawing the steel plate from the physical model, as shown in Figure 3(a). (3) Drawing device, which is connected with the steel plates by connecting pieces, is shown in Figure 3(b). By turning the handle at a constant speed, the steel plate will be pulled from the physical model to simulate the mining of coal seam.

2.5. Storage Tank. In order to guarantee the stability of water pressure and water yield, the storage tank is designed, as shown in Figure 4. The storage tank is cylindric; the thickness and internal diameter and height are $10 \mathrm{~mm}, 300 \mathrm{~mm}$, and 


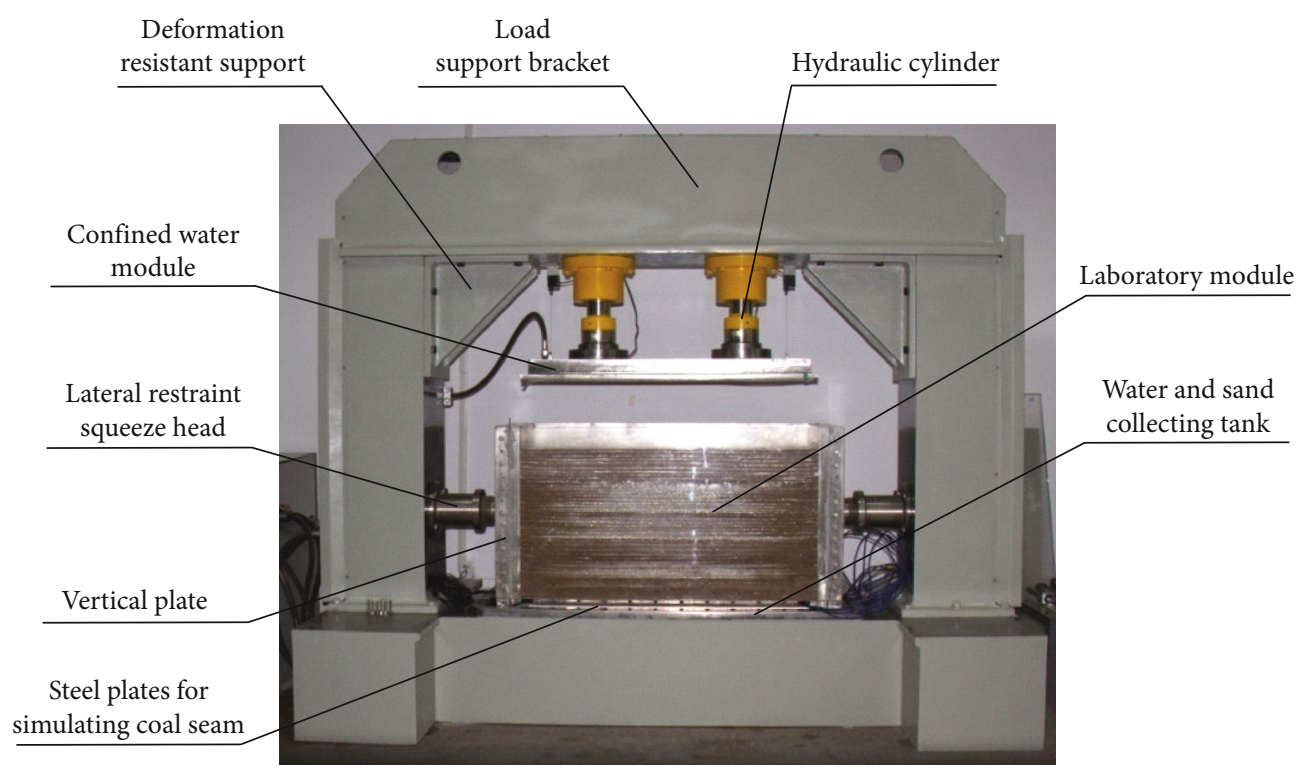

Figure 1: Structural diagrams of mechanical system.

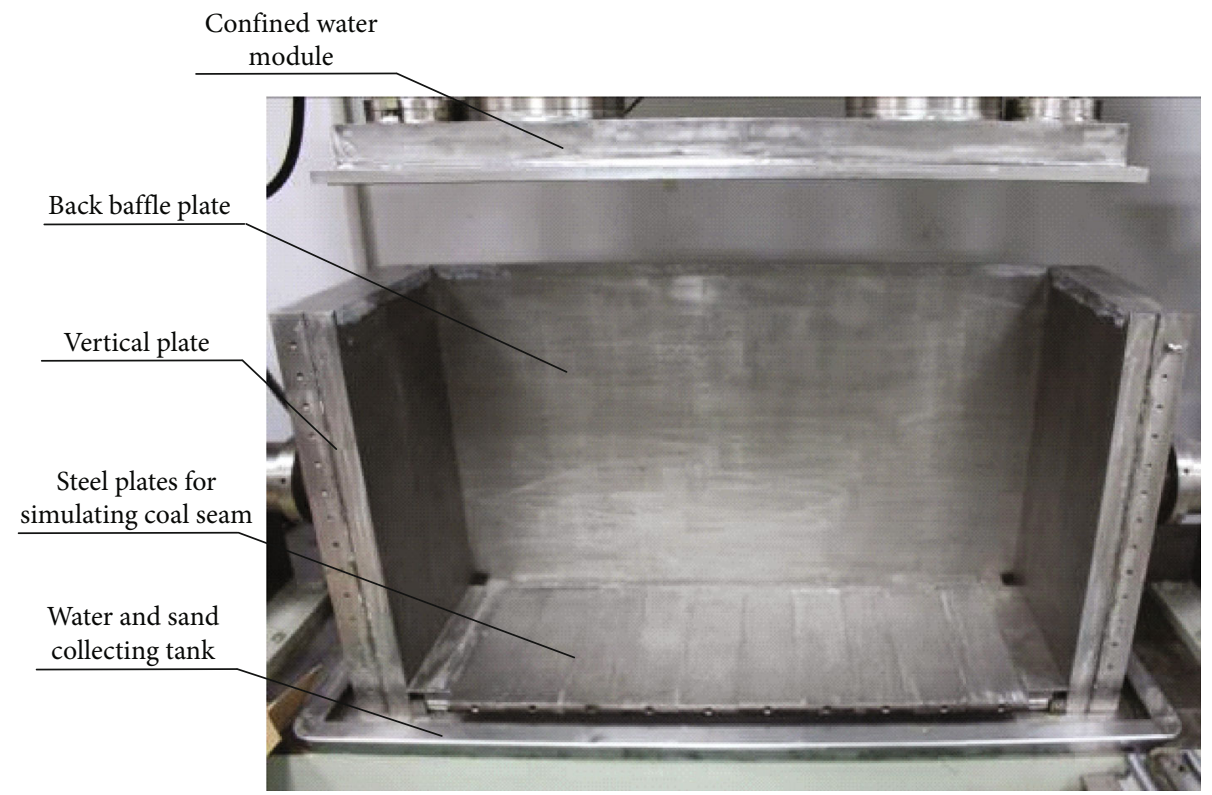

FIgURE 2: Structural diagrams of laboratory module.

$1000 \mathrm{~mm}$, respectively. The flowmeter and water pressure sensor are installed in the water outlet of storage tank, which are located in the back of storage tank.

2.6. Control System. The control system consists of console and servo loading system, as shown in Figure 5. The servo loading system consists of servo control system of water pressure and water yield and servo control system of displacement and stress. (1) Console is fully automated; five basic parameters can be collected into a database in real time, such as time, displacement, loading, water pressure, and water yield. The maximum sampling frequency is $10 \mathrm{HZ}$. (2) Servo control system of water pressure and water yield can fill the testing chamber with water by setting water pressure or water yield. The maximum water pressure is $2 \mathrm{MPa}$, the maximum water supply is $150 \mathrm{~L} / \mathrm{h}$, and the accuracy is $0.01 \mathrm{MPa}$. (3) Servo control system of displacement and loading can control the loading head by setting displacement or loading. The meter full scale of displacement is $400 \mathrm{~mm}$, and the accuracy is $0.01 \mathrm{~mm}$. The maximum loading is $1000 \mathrm{KN}$, and the accuracy is $0.01 \mathrm{KN}$.

\section{Experimental Scheme of Physical Simulation}

3.1. Engineering Background. Shendong mining area is located in western region of China, which is one of the largest 


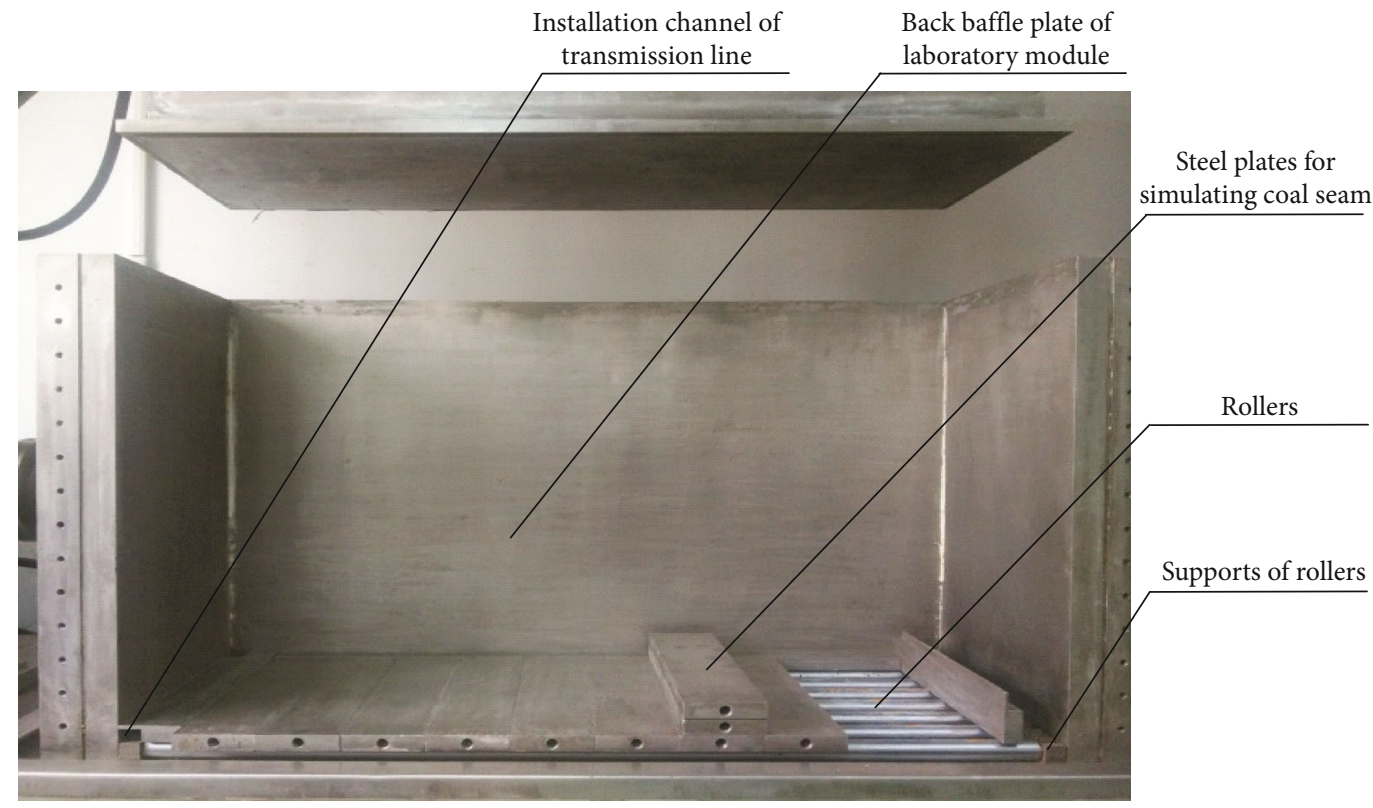

(a) Stainless steel plates and rollers

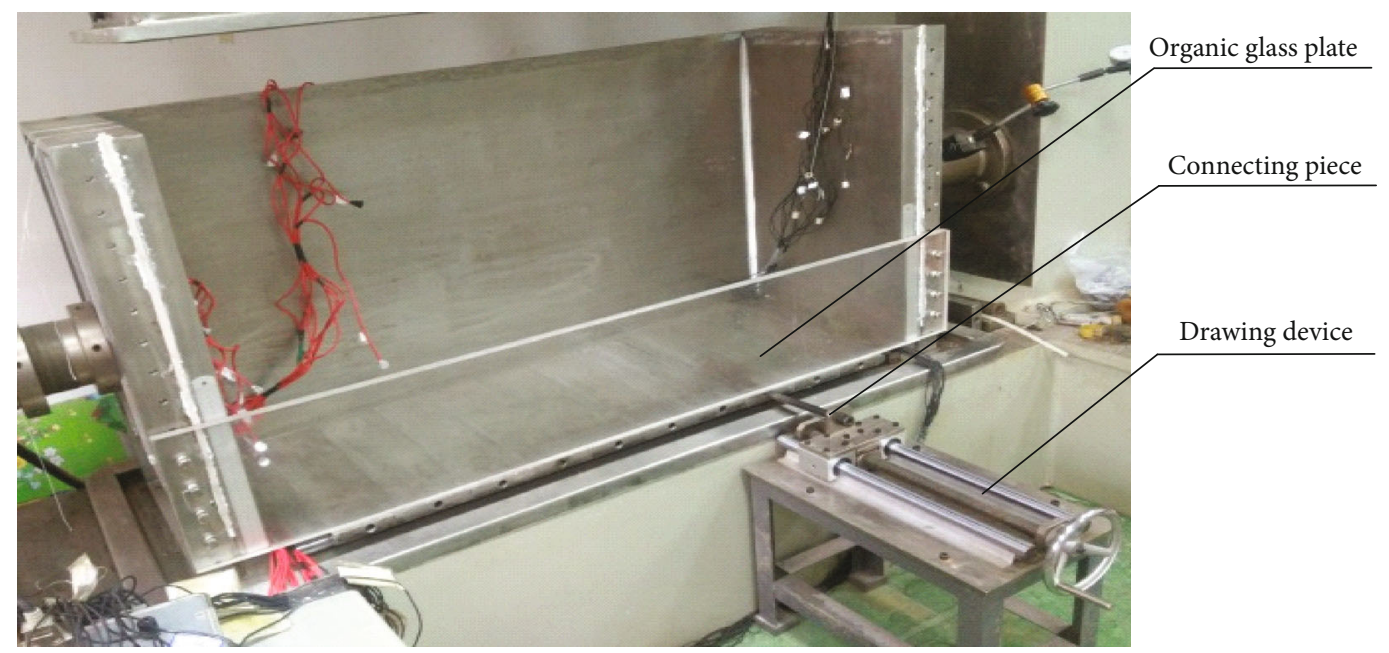

(b) Drawing device

Figure 3: Coal seam mining simulator.

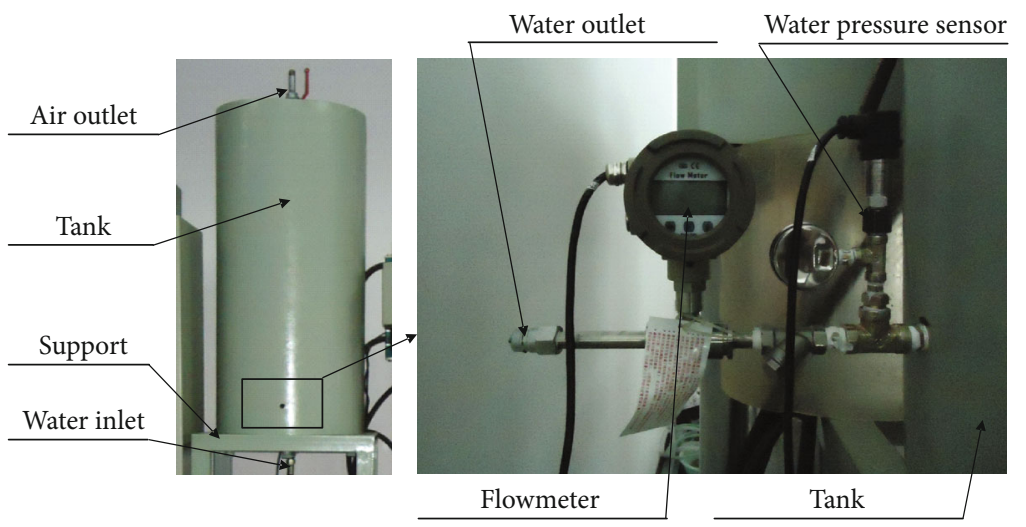

FIGURE 4: Storage tank. 


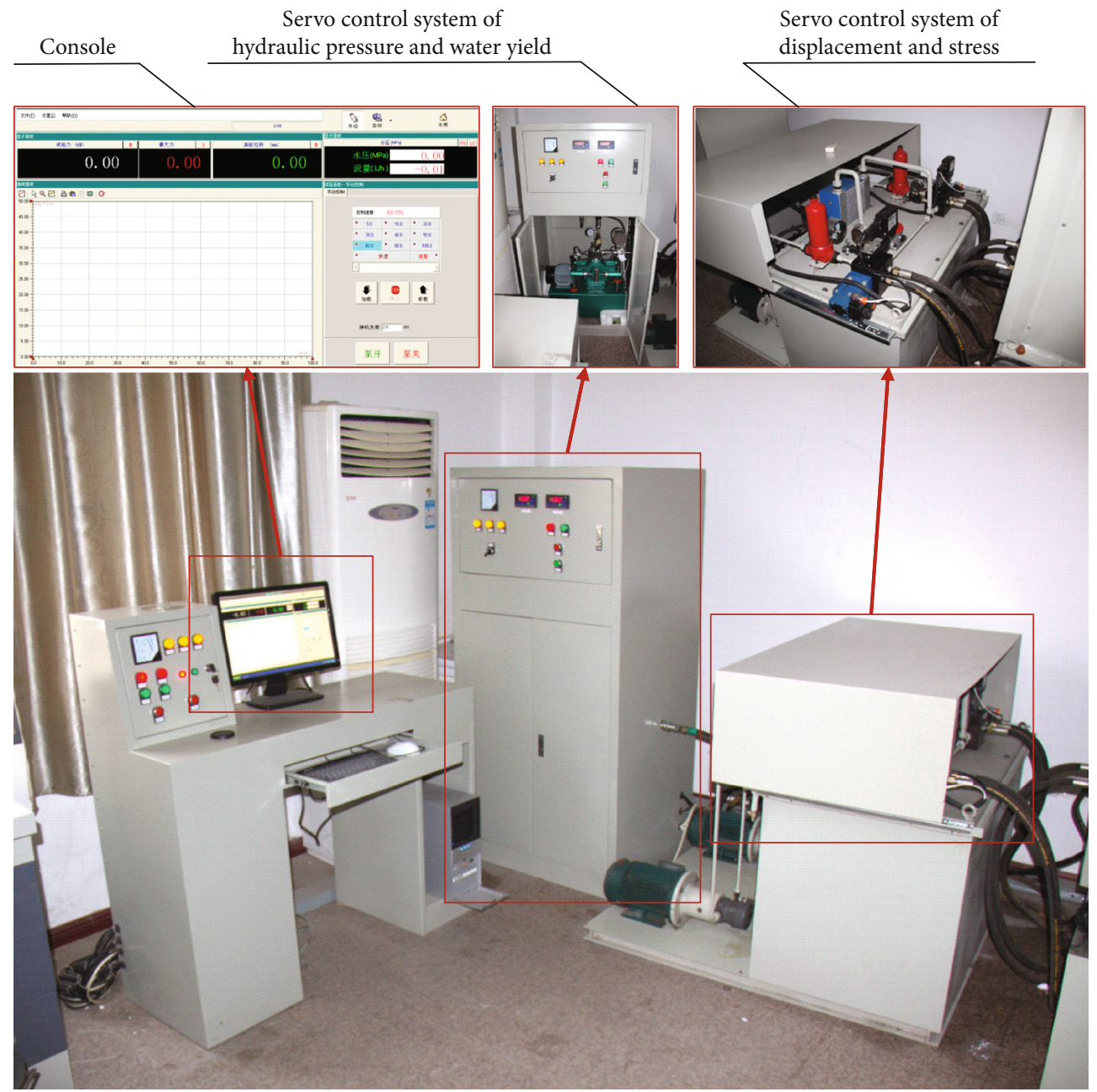

Figure 5: Control system.

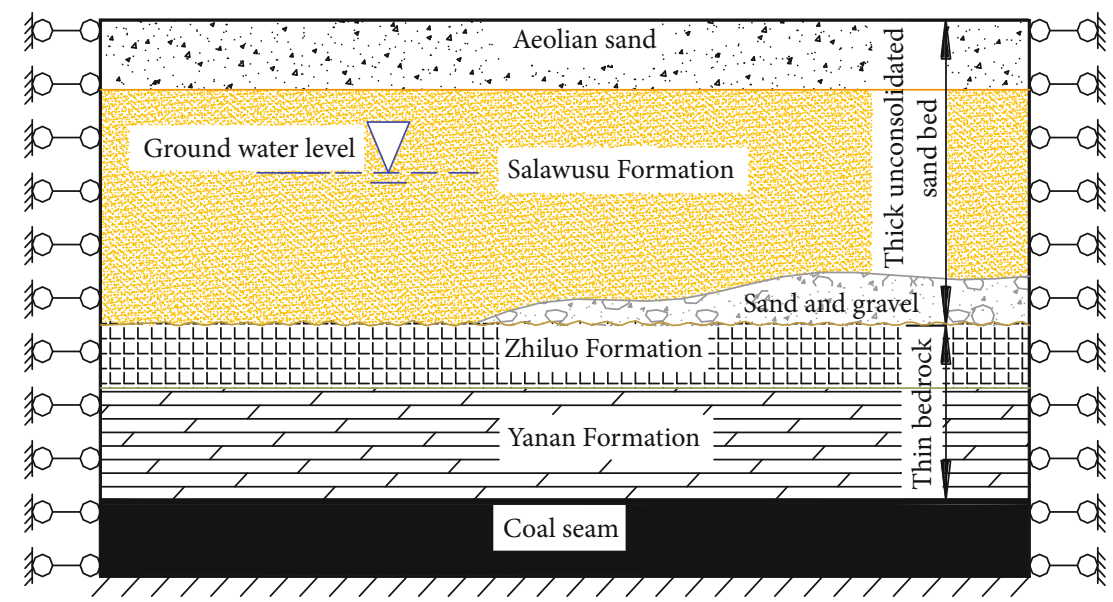

Figure 6: Combination of coal bearing strata.

coal mining area in China [31-33]. In the south of Shendong mining area, the thickness of coal seam is larger, the buried depth is shallower, the bedrock is thinner, and there is also a thick unconsolidated sand bed near the surface. The combination of coal bearing strata is shown in Figure 6.
(1) The Quaternary is mainly consists of Holocene and Salawusu Formation (belonging to Upper Pleistocene); the average thickness of it is $15-50 \mathrm{~m}$. Holocene consists of aeolian sand, loess, and sand and gravel. The average thickness of aeolian sand aquifer 
TABLE 1: Similar material ratio of different strata.

\begin{tabular}{|c|c|c|c|c|c|c|}
\hline \multirow[b]{2}{*}{$\begin{array}{l}\text { Number of } \\
\text { stratum }\end{array}$} & \multirow[b]{2}{*}{ Lithology } & \multicolumn{2}{|c|}{ Real rock stratum } & \multicolumn{2}{|c|}{ Similar material } & \multirow[b]{2}{*}{$\begin{array}{l}\text { Material ratio (sand: paraffin: Vaseline } \\
\text { hydraulic oil: lime carbonate) }\end{array}$} \\
\hline & & Thickness/m & $\begin{array}{c}\text { Uniaxial } \\
\text { compressive } \\
\text { strength/MPa }\end{array}$ & Thickness/m & $\begin{array}{c}\text { Uniaxial } \\
\text { compressive } \\
\text { strength } / \mathrm{kPa}\end{array}$ & \\
\hline 10 & $\begin{array}{l}\text { Aeolian } \\
\text { sand }\end{array}$ & 50 & - & 0.20 & - & Color sand \\
\hline 9 & Mudstone & 10 & 18.8 & 0.04 & 50.1 & $40: 0.4: 1: 1: 3$ \\
\hline 8 & $\begin{array}{l}\text { Fine } \\
\text { sandstone }\end{array}$ & 10 & 22.4 & 0.04 & 59.7 & $40: 0.43: 1: 1: 3$ \\
\hline 7 & $\begin{array}{l}\text { Medium } \\
\text { sandstone }\end{array}$ & 7.5 & 32.2 & 0.03 & 85.9 & $40: 0.5: 1: 1: 3$ \\
\hline 6 & $\begin{array}{l}\text { Arenaceous } \\
\text { mudstone }\end{array}$ & 5 & 36.7 & 0.02 & 97.9 & $40: 0.54: 1: 1: 3$ \\
\hline 5 & $\begin{array}{c}\text { Fine } \\
\text { sandstone }\end{array}$ & 7.5 & 46.9 & 0.03 & 125.1 & $40: 0.62: 1: 1: 3$ \\
\hline 4 & Mudstone & 5 & 30.1 & 0.02 & 80.3 & $40: 0.5: 1: 1: 3$ \\
\hline 3 & $\begin{array}{l}\text { Medium } \\
\text { sandstone }\end{array}$ & 7.5 & 40.5 & 0.03 & 108.0 & $40: 0.6: 1: 1: 3$ \\
\hline 2 & $\begin{array}{c}\text { Fine } \\
\text { siltstone }\end{array}$ & 10 & 35.7 & 0.04 & 95.2 & $40: 0.53: 1: 1: 3$ \\
\hline 1 & Mudstone & 5 & 26.5 & 0.02 & 70.7 & $40: 0.46: 1: 1: 3$ \\
\hline 0 & Coal seam & 7.5 & 10.4 & 0.03 & - & Steel plates for simulating the coal seam \\
\hline
\end{tabular}

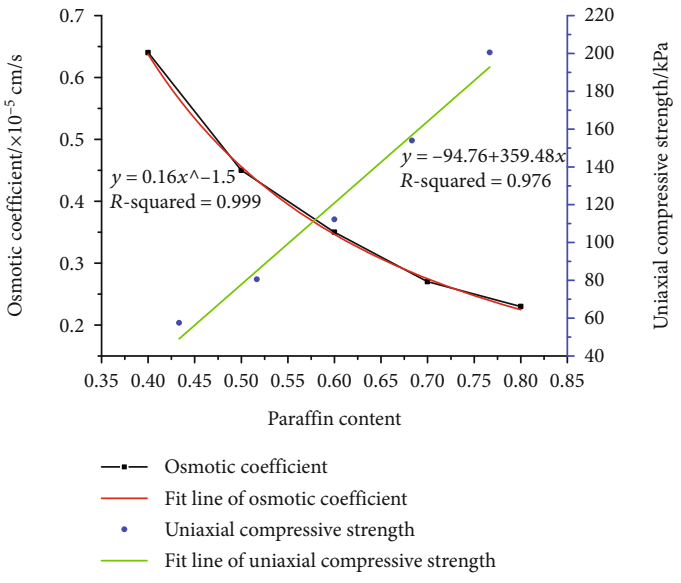

Figure 7: Effect of paraffin content to the parameters of similar material.

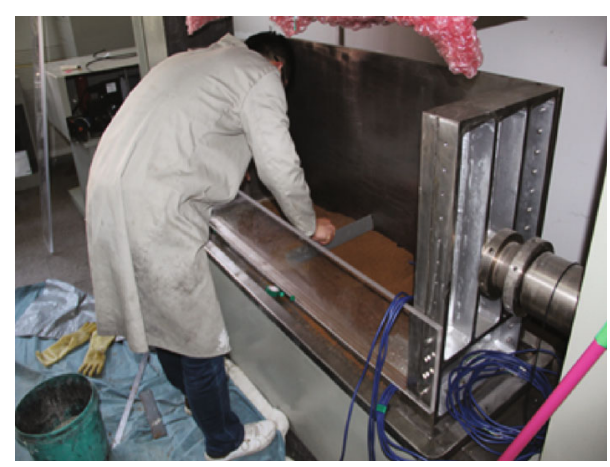

FIgure 8: Physical model laying.

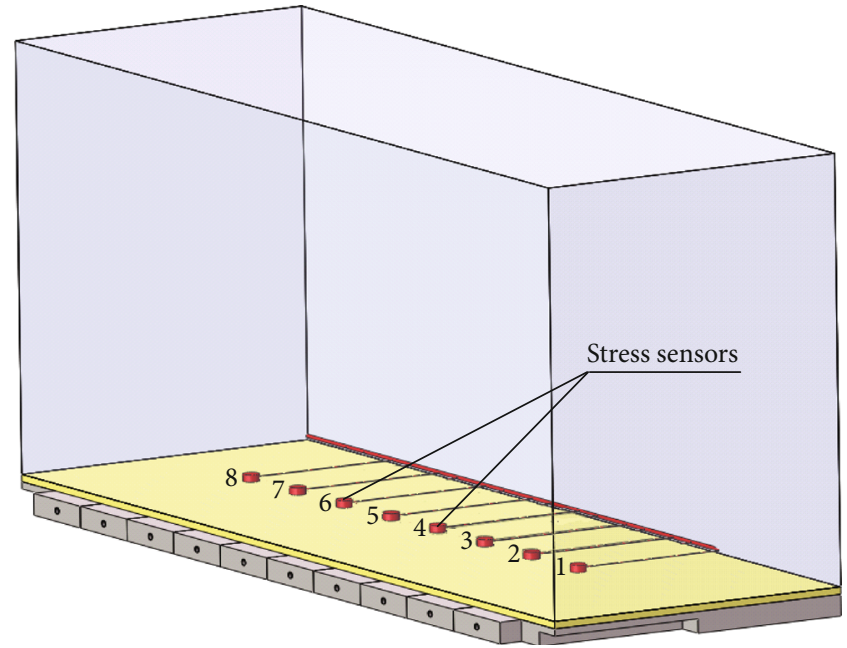

Figure 9: Layout of stress sensors.

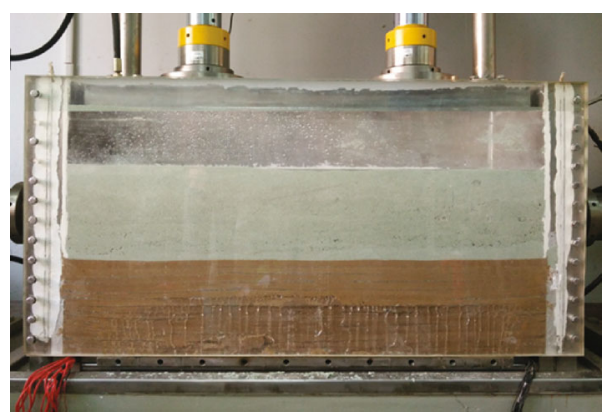

FIGURE 10: Unexcavated similar material model. 

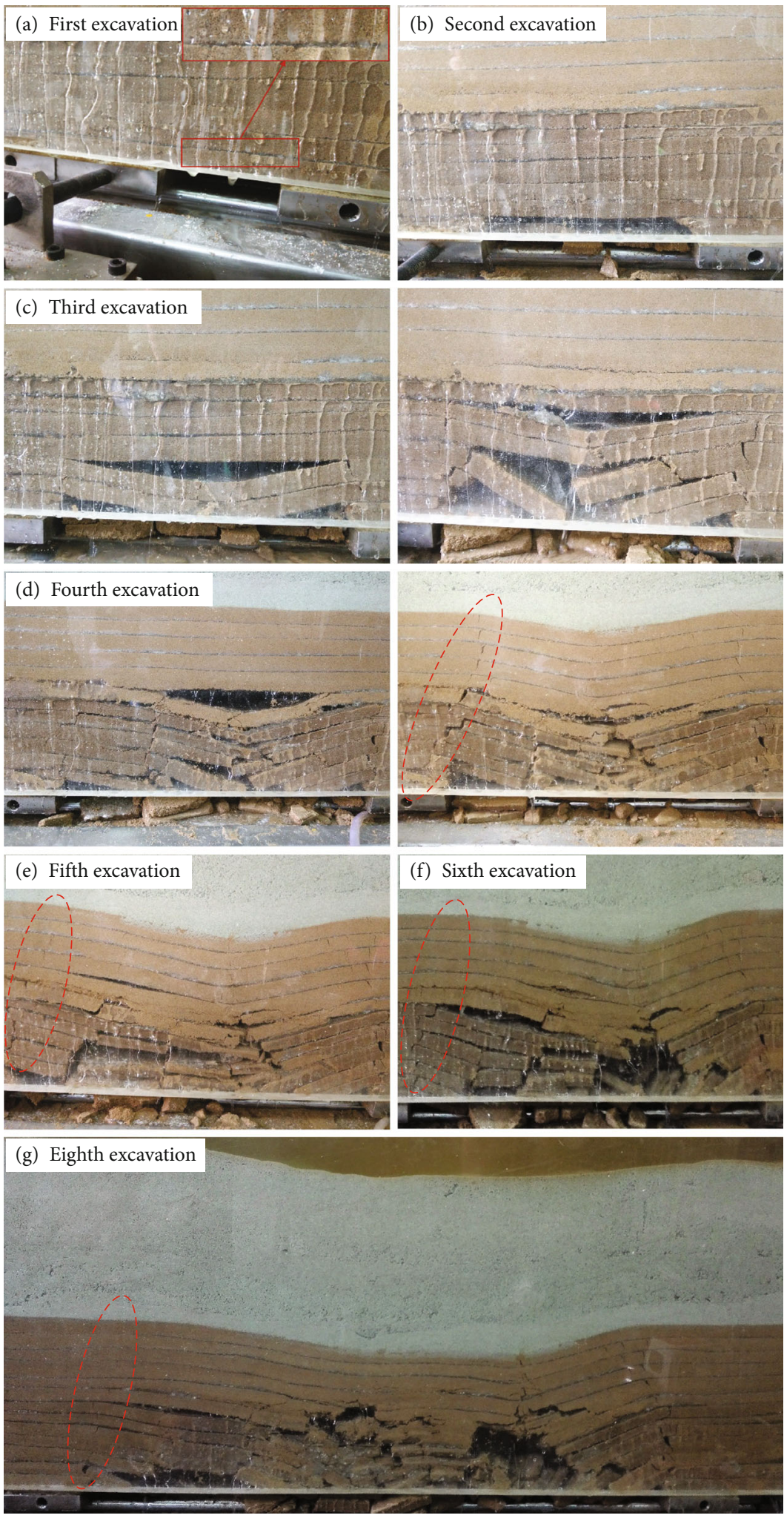

FIGURE 11: Deformation and failure of overlying strata.

is about $3 \mathrm{~m}$, the depth of ground water level is $0-5 \mathrm{~m}$, the osmotic coefficient is $0.061 \mathrm{~m} / \mathrm{d}$, and specific yield is $0.0188 \mathrm{~L} /(\mathrm{s} \cdot \mathrm{m})$, so the water yield property of aquifer is weak. Salawusu Formation is mainly fluviatile and lacustrine sediment, the upper of Salawusu For- mation consists of fine sand and silt, the middle of Salawusu Formation is medium sand and coarse sand, and the lower of Salawusu Formation is sand and gravel. The thickness of Salawusu Formation aquifer is $10-30 \mathrm{~m}$, the osmotic coefficient is 0.88 - 
$17.5 \mathrm{~m} / \mathrm{d}$, and the specific yield is $0.10-2.11 \mathrm{~L} /(\mathrm{s} \cdot \mathrm{m})$, so the water yield property of Salawusu Formation aquifer is medium to strong, which is the main source of water-sand inrush accident

(2) Jurassic is mainly consists of Zhiluo Formation (belonging to Middle Jurassic) and Yanan Formation (belonging to Lower Jurassic). Zhiluo Formation is fluviatile and lacustrine sediment; the lithology of it is argillaceous sandstone, which is the main impermeable stratum above the coal seam, and the average thickness is only $38.4 \mathrm{~m}$. Zhiluo Formation is absent in some area, so the coal seam is covered by Quaternary directly. Yanan Formation is also fluviatile and lacustrine sediment, which is the coal bearing strata and consists of siltstone, mudstone dunnet shale, and coal seam. Because of scour action, Zhiluo Formation and Yanan Formation become thin and even disappear, which shortens the distance between the Quaternary aquifer and coal seam greatly and increases the risk of water-sand inrush during coal mining

3.2. Parameter Determination of Physical Model. The geometric similarity factor of physical model is set as 250; the length, width, and height of physical model are $1200 \mathrm{~mm}$, $400 \mathrm{~mm}$, and $500 \mathrm{~mm}$, respectively, which represent that the actual strike length, dip length, and strata thickness are $300 \mathrm{~m}, 100 \mathrm{~m}$, and $125 \mathrm{~m}$, respectively. From the coal seam to the surface, the strata are divided into 11 layers, as shown in Table 1. The unconsolidated sand bed is simulated by color sand for increasing the intuition of sand inrush. The thickness and width of steel plates for simulating the coal seam are $30 \mathrm{~mm}$ and $105 \mathrm{~mm}$, respectively, which represent that the actual mining height and mining interval are $7.5 \mathrm{~m}$ and $26.25 \mathrm{~m}$, respectively. In order to realize the three dimensional simulation of working face mining, each steel plate for simulating the coal seam is pulled from the physical model at a constant speed; the time interval of adjacent steel plate is one hour.

3.3. Similar Material Ratio. In the process of water-sand inrush simulated test, considering the involvement of water, the selected similar material should be nonhydrophilic. A series of nonhydrophilic composite materials with lower intensity are developed to simulate the coal measure strata, which are consist of sand, paraffin, Vaseline, hydraulic oil, and lime carbonate; the sand is aggregate, the paraffin and Vaseline are both binding agent, the hydraulic oil is blender, and the lime carbonate is used for regulating permeability. As we know, the stress similarity factor is equal to the product of geometric similarity factor and unit weight similarity factor, the geometric similarity factor is 250 , and the unit weight similarity factor is 1.5 , so the stress similarity factor is 375 . In this test, the strength of similar materials needs to be distributed between 50.1 and $125.1 \mathrm{kPa}$, the paraffin content is selected as the main factor to the strength change of similar

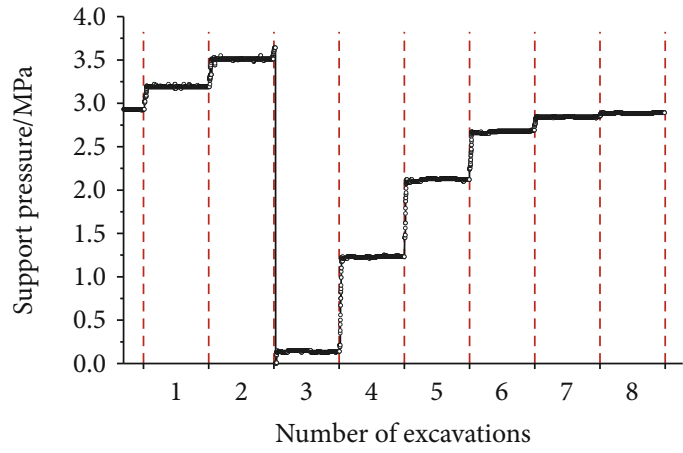

FIGURE 12: Pressure changes monitored by No.2 stress sensor.

materials, the test result of similar material ratio is shown in Figure 7. There is an approximate linear relationship between paraffin content and strength of similar materials; the $R$-squared is 0.976 . Similar material ratio of different strata is shown in Table 1.

3.4. Production of Physical Model. Before laying the physical model, steel plates for simulating the coal seam should be reset firstly, and the signal transmission lines of stress sensors should be imported into the laboratory module through the installation channel of transmission line. The physical model is laid layer by layer. According to the similar material ratio of different strata, the required mass of each component can be calculated exactly. The sand and lime carbonate are stirred uniformly and heated to about $80^{\circ} \mathrm{C}$ with the wok. The paraffin, Vaseline, and hydraulic oil are heated to about $60^{\circ} \mathrm{C}$ with water bath kettle until they become liquid completely. Then, they are mixed quickly, poured into the laboratory module, and processed into the similar stratum, as shown in Figure 8. The mica powder is used between adjacent strata as the boundary. Eight stress sensors are buried above the coal seam in the physical model for monitoring the support pressure change of overlying strata caused by mining, as shown in Figure 9. The unexcavated similar material model is shown in Figure 10.

3.5. Steps of Physical Model Excavation. The steps of watersand inrush simulated experiment are as follows: (1) starting the servo control system of displacement and stress, using displacement control mode to adjust the gap between the load head and test materials until the gap is about $100 \mathrm{~mm}$; (2) starting the servo control system of water pressure and water yield, using water pressure control mode to keep the water pressure in the laboratory module at $0.1 \mathrm{MPa}$; and (3) taking two minutes to pull the steel plate for simulating the coal seam from the physical model at a constant speed, the time interval of adjacent steel plate is one hour. During the working face mining, the deformation and failure of overlying strata, fissure extension of overlying strata, and the formation of water-sand channels could be observed directly through the organic glass plate. The support pressure change of overlying strata caused by mining could be monitored by stress sensors in real time. The water pressure and water yield could also be monitored by water pressure sensor and flowmeter in real time. 


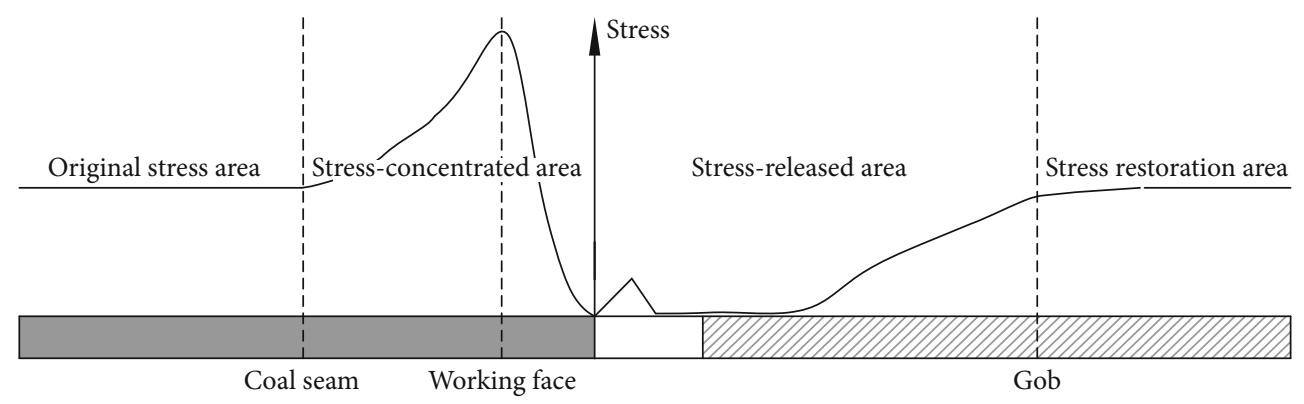

FIGURE 13: Distribution of support pressure around the working face.

\section{Experimental Results of Physical Simulation}

4.1. Analysis of the Overlying Strata Deformation and Failure. After the first excavation, only the immediate roof presents slight bed separation, and there is no fissure, as shown in Figure 11(a). During the second excavation, the bed separation space between adjacent stratum becomes larger gradually, and the immediate roof breaks and falls into the gob. As time goes on, multiple strata above the immediate roof present bed separation, as shown in Figure 11(b). During the third excavation, because the span of some overlying strata exceeds the limit, the curved strata cannot bear their own weight, break into blocks, and fall into the gob; the caved zone extends to No.4 stratum (mudstone), but the mininginduced fractures of overlying strata above the caved zone are not obvious, as shown in Figure 11(c).

During the fourth excavation, the height of caved zone becomes higher, and the mining-induced fractures of overlying strata above the caved zone become obvious and extend to the bottom of the unconsolidated sand bed gradually, which serves as pathways between the unconsolidated sand bed and working face, triggering water-sand inrush, as shown in Figure 11(d). During the subsequent excavation, the opening of mining-induced vertical fractures decreases gradually and even disappears, as shown in Figures 11(e)-11(g).

4.2. Regularity of Support Pressure Distribution. Throughout the working face mining, the pressure changes monitored by No.2 stress sensor are shown in Figure 12. During the first and second excavation, No.2 stress sensor is located in front of the working face; the data monitored by it reflect the advance support pressure, which is greater than the original stress. During the third excavation, No.2 stress sensor is just located above the working face; the data monitored by it display the tendency of increasing first and then decreasing sharply and increasing slowly again. During the subsequent excavation, No.2 stress sensor is located behind the working face; the data monitored by it display the tendency of increasing slowly, which are infinitely close to the original stress. The distribution of support pressure around the working face can be divided into 4 areas, that is, the original stress area, the stress-concentrated area, the stress-released area, and the stress restoration area, as shown in Figure 13.

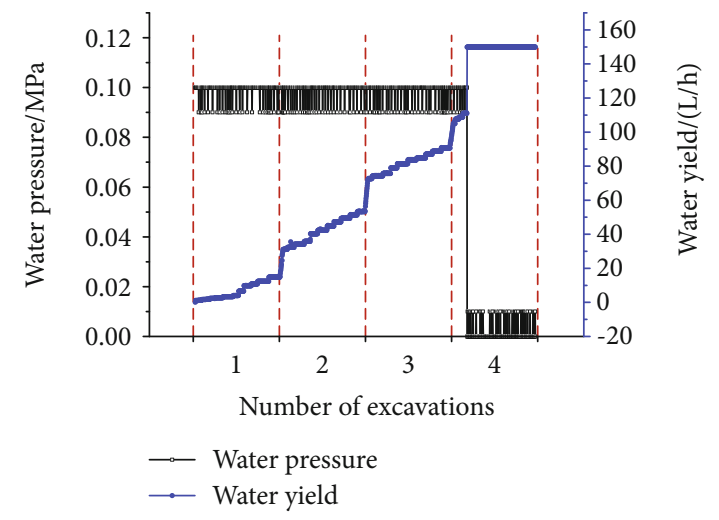

FIGURE 14: Changes of water pressure and water yield.

4.3. Relationship between Water Pressure, Water Yield, and Water-Sand Inrush. Before the mining-induced vertical fractures of overlying strata pass through the entire bedrock and connect the unconsolidated sand bed, the water pressure in the laboratory module can maintain a dynamic constant of $0.1 \mathrm{MPa}$, but a certain amount of water yield occurs. The water seepage becomes more and more obvious with the working surface mining. After the fourth excavation, the mininginduced vertical fractures of overlying strata connect the unconsolidated sand bed, which serves as pathways between the unconsolidated sand bed and working face, triggering water-sand inrush. The water pump suddenly accelerates, and the water yield suddenly increases to the extreme value of $150 \mathrm{~L} / \mathrm{h}$. The water pressure rapidly drops to $0 \mathrm{MPa}$, and a small amount of colored sand enters into the fractures of overlying strata and flows out with the water. The changes of water pressure and water yield are shown in Figure 14.

\section{Conclusions}

(1) In western region of China, the water-sand inrush across overlying strata fissures caused by mining threatens the mine safety production seriously. In order to study the development of water-sand inrush across overlying strata fissures caused by mining, a simulated test system consisted of load support bracket, laboratory module, confined water module, coal seam mining simulator, storage tank, and control system is developed 
(2) The combination of coal bearing strata in the south of Shendong mining area is looked on as the engineering background, and a series of new nonhydrophilic composite materials with lower intensity are developed to simulate the coal measure strata

(3) The excavation of physical model can reproduce the whole process of water-sand inrush across overlying strata fissures caused by mining to the life. Under the action of mining and water pressure, after the fourth excavation, the mining-induced vertical fractures of overlying strata pass through the entire bedrock and connect the unconsolidated sand bed, which serves as pathways between the unconsolidated sand bed and working face, triggering watersand inrush. The water pump suddenly accelerates, and the water yield suddenly increases to the extreme value of $150 \mathrm{~L} / \mathrm{h}$. The water pressure rapidly drops to $0 \mathrm{MPa}$, and a small amount of colored sand enters into the fractures of overlying strata and flows out with the water. The distribution of support pressure around the working face can be divided into 4 areas obviously, that is, the original stress area, the stressconcentrated area, the stress-released area, and the stress restoration area

(4) Test results show that the system is stable and reliable, which have important significance for studying the formation mechanism of water-sand inrush across overlying strata fissures further

\section{Data Availability}

The data used to support the findings of this study are included within the article.

\section{Conflicts of Interest}

The authors declare no conflicts of interest.

\section{Acknowledgments}

This work was supported by the National Natural Science Foundation of China (51704152) and the Natural Science Foundation of Shandong Province (ZR2017BEE001).

\section{References}

[1] Q. X. Huang, "Ground pressure behavior and definition of shallow seams," Chinese Journal of Rock Mechanics and Engineering, vol. 21, no. 8, pp. 1174-1177, 2002.

[2] X. X. Miao, C. S. Wang, and H. B. Bai, "Hydrogeologic characteristics of mine water hazards in shendong mining area," Journal of Mining and Safety Engineering, vol. 27, no. 3, pp. 285-294, 2010.

[3] X. Q. Fang, X. J. Hao, and Y. W. Lan, "Determination of reasonable forced caving interval in shallow-buried seam with hard and thin bedrock," Chinese Journal of Rock Mechanics and Engineering, vol. 29, no. 2, pp. 388-393, 2010.
[4] L. M. Fan, D. X. Ma, H. Jiang, and S. Chen, "Risk evaluation on water and sand inrush in ecologically fragile coal mine," Journal of China Coal Society, vol. 41, no. 3, pp. 531-536, 2016.

[5] F. Du, Z. H. Li, G. H. Jiang, and Z. Q. Chen, "Types and mechanism of water and inrush disaster in west coal mine," Journal of China Coal Society, vol. 42, no. 7, pp. 1846-1853, 2017.

[6] J. C. Zhong, H. W. Zhou, Y. F. Zhao, Y. Q. Liu, H. Y. Yi, and D. J. Xue, "The two-phase flow of water-sand inrush under shallow coal seam mining: a coupled numerical study," Engineering Mechanics, vol. 34, no. 12, pp. 229-238, 2017.

[7] L. M. Fan, "Controlling technological study on suffusion hazard of coal shaft," Geological Hazard and Control, vol. 7, no. 4, pp. 35-38, 1996.

[8] Y. P. Wu and S. M. Lu, "Analysis of sand inrush in shallow buried stope," Ground Pressure and Strata Control, vol. 4, pp. 57-58, 2004.

[9] J. Zhang and Z. J. Hou, "Study on sand inrush disaster in shallow seam mining," Journal of Hunan University of Science and technology: Natural Science Edition, vol. 20, no. 3, pp. 15-18, 2005.

[10] H. J. Li, J. H. Li, L. Li, H. Xu, and J. J. Wei, "Prevention of water and sand inrush during mining of extremely thick coal seams under unconsolidated Cenozoic alluvium," Bulletin of Engineering Geology and the Environment, vol. 79, no. 6, pp. 3271-3283, 2020.

[11] W. H. Sui, J. W. Liu, B. L. Gao, and Y. K. Liang, “A review on disaster mechanism of quicksand with a high potential energy due to mining and its prevention and control," Journal of China Coal Society, vol. 44, no. 8, pp. 2419-2426, 2019.

[12] Q. F. Zhao, N. Zhang, C. L. Han et al., "Simulation experiment of water-sand inrush during the mining of the shallow coal seam under roof aquifer with thin bedrock," Journal of Mining and Safety Engineering, vol. 34, no. 3, pp. 444-451, 2017.

[13] X. Yang, Z. H. Xu, T. H. Yang, B. Yang, and W. H. Shi, "Incipience condition and migration characteristics of aeolian-sand aquifer in a typical western mine," Rock and Soil Mechanics, vol. 39 , no. 1, pp. 21-28, 2018.

[14] D. Ma, H. Y. Duan, W. T. Liu, X. T. Ma, and M. Tao, "Watersediment two-phase flow inrush hazard in rock fractures of overburden strata during coal mining," Mine Water and the Environment, vol. 39, no. 2, pp. 308-319, 2020.

[15] Q. Wu, K. Xu, and W. Zhang, "Further research on "three maps-two predictions " method for prediction on coal seam roof water bursting risk," Journal of China Coal Society, vol. 41, no. 6, pp. 1341-1347, 2015.

[16] W. F. Yang, X. H. Xia, B. L. Pan, C. Gu, and J. Yue, “The fuzzy comprehensive evaluation of water and sand inrush risk during underground mining," Journal of Intelligent \& Fuzzy Systems, vol. 30, no. 4, pp. 2289-2295, 2016.

[17] W. Q. Zhang, Z. Y. Wang, X. X. Zhu, W. Li, B. Gao, and H. L. $\mathrm{Yu}$, "A risk assessment of a water-sand inrush during coal mining under a loose aquifer based on a factor analysis and the fisher model," Journal of Hydrologic Engineering, vol. 25, no. 8, pp. 1-12, 2020.

[18] G. W. Fan, D. S. Zhang, S. Z. Zhang, and C. G. Zhang, “Assessment and prevention of water and sand inrush associated with coal mining under a water-filled buried gully: a case study," Mine Water and the Environment, vol. 37, no. 3, pp. 565576, 2018.

[19] Y. Xu, Y. Luo, J. Li, K. Li, and X. Cao, "Water and sand inrush during mining under thick unconsolidated layers and thin 
bedrock in the Zhaogu no. 1 coal mine, China," Mine Water and the Environment, vol. 37, no. 2, pp. 336-345, 2018.

[20] Y. G. Lu, Q. H. Xiao, and J. L. Cheng, "Mechanism and prevention of water and inrush in soft rock with weakly abundant water: a case study in Shanghai temple mining area," Journal of China Coal Society, vol. 44, no. 10, pp. 3154-3163, 2019.

[21] H. L. Wang, S. J. Chen, and W. J. Guo, "Development and application of test system for water-sand inrush," Journal of Mining and Safety Engineering, vol. 36, no. 1, pp. 72-79, 2019.

[22] K. Zhang, B. Y. Zhang, J. F. Liu, D. Ma, and H. B. Bai, “Experiment on seepage property and sand inrush criterion for granular rock mass," Geofluids, vol. 2017, Article ID 9352618, 10 pages, 2017.

[23] X. Yang, Y. J. Liu, M. Xue, T. H. Yang, and B. Yang, "Experimental investigation of water-sand mixed fluid initiation and migration in porous skeleton during water and sand inrush," Geofluids, vol. 2020, Article ID 8679861, 18 pages, 2020.

[24] B. Yang, T. H. Yang, Z. H. Xu, and X. Yang, "Critical velocity of sand inrush and flow characteristics of water-sand in thick unconsolidated formations of mine in western China," Journal of Northeastern University(Natural Science), vol. 39, no. 11, pp. 1648-1652, 2018.

[25] Y. Liang, Z. D. Tan, and G. J. Li, "Simulation test research on water and soil outbursts of weak binding soil," Journal of Xian Highway University, vol. 16, no. 1, pp. 19-22, 1996.

[26] A. P. Tang, Y. Dong, Z. D. Tan, and A. H. Wen, "Mechanism of sandy-silt seepage deformation in mine under vibration," Earthquake Engineering and Engineering Vibration, vol. 19, no. 2, pp. 132-135, 1999.

[27] W. H. Sui, G. T. Cai, and Q. H. Dong, "Experimental research on critical percolation gradient of quicksand across overburden fissures due to coal mining near unconsolidated soil layers," Chinese Journal of Rock Mechanics and Engineering, vol. 26, no. 10, pp. 2084-2091, 2007.

[28] W. H. Sui and Q. H. Dong, "Variation of pore water pressure and its precursor significance for quicksand disasters due to mining near unconsolidated formations," Chinese Journal of Rock Mechanics and Engineering, vol. 27, no. 9, pp. 19081916, 2008.

[29] W. F. Yang, W. H. Sui, Y. B. Ji, and G. R. Zhao, "Experimental research on the movement process of mixed water and sand flow across overburden fissures in thin bedrock induced by mining," Journal of China Coal Society, vol. 34, no. 4, pp. 686-692, 2012.

[30] W. F. Yang, L. Jin, and X. Q. Zhang, "Simulation test on mixed water and sand inrush disaster induced by mining under the thin bedrock," Journal of Loss Prevention in the Process Industries, vol. 57, pp. 1-6, 2019.

[31] Y. Q. Jiao, S. M. Wang, L. M. Fan, L. Q. Wu, H. Rong, and F. Zhang, "Key elements and framework model of groundwater system in Jurassic coal measures of Ordos Basin," Journal of China Coal Society, vol. 45, no. 7, pp. 2411-2422, 2020.

[32] S. N. Dong, Y. D. Ji, H. Wang et al., "Prevention and control technology and application of roof water disaster in Jurassic coal field of Ordos Basin," Journal of China Coal Society, vol. 45, no. 7, pp. 2367-2375, 2020.

[33] Y. Wang, Q. Wu, X. Ding, B. Gao, and Z. G. Pu, "Key technologies for prevention and control of roof water disaster at sources in deep Jurassic seams," Journal of China Coal Society, vol. 44, no. 8, pp. 2449-2459, 2019. 